Article

\title{
Development of the Morphology and the Band Gap Energy of Co-Si Nanofibers by Inserting Zirconium and Titanium with Dual Anions Intercalation Process
}

\author{
Osama Saber ${ }^{1,2, * \mathbb{D}}$, Nagih M. Shaalan ${ }^{1,3, *}$, Aya Osama ${ }^{4}$ and Adil Alshoaibi ${ }^{1}$ \\ 1 Department of Physics, College of Science, King Faisal University, Al-Hassa 31982, P.O. Box 400, \\ Saudi Arabia; adshoaibi@kfu.edu.sa \\ 2 Egyptian Petroleum Research Institute, Nasr City, P.O. Box 11727, Cairo, Egypt \\ 3 Physics Department, College of Science, Assiut University, Assiut 71516, Egypt \\ 4 Department of Chemistry, College of Science, King Faisal University, Al-Hassa 31982, P.O. Box 400, \\ Saudi Arabia; ayamohamed19984@yahoo.com \\ * Correspondence: osmohamed@kfu.edu.sa (O.S.); nmohammed@kfu.edu.sa (N.M.S.); \\ Tel.: +966-13-589-9440 (O.S.)
}

Received: 21 October 2019; Accepted: 4 November 2019; Published: 8 November 2019

\begin{abstract}
The plate-like structure is the most familiar morphology for conventional layered double hydroxides (LDHs) in case their structures consist of divalent and trivalent cations in their layers. In this study, nanofibers and nanoneedles of $\mathrm{Co}-\mathrm{Si} \mathrm{LDHs}$ were prepared for the first time. By the inclusion of zirconium inside the nanolayers of LDH structures, their plates were formed and transformed to nanofibers. These nanofibers were modified by the insertion of titanium to build again plate-like morphology for the LDH structure. This morphology controlling was studied and explained by a dual anions intercalation process. The optical properties of Co-Si LDHs indicated that the incorporation of zirconium within their nanolayers decreased the band gap energy from $4.4 \mathrm{eV}$ to $2.9 \mathrm{eV}$. Following the same behavior, the insertion of titanium besides zirconium within the nanolayers of Co-Si LDHs caused a further reduction in the band gap energy, which became $2.85 \mathrm{eV}$. Although there is no data for the optical properties of Co-Si LDHs in the literature, it is interesting to observe the low band gap energy for $\mathrm{Co}-\mathrm{Si} \mathrm{LDH}$ to become more suitable for optical applications. These results concluded that the reduction of the band gap energy and the formation of nanofibers introduce new optical materials for developing and designing optical nanodevices.
\end{abstract}

Keywords: Co-Si LDHs; nanofibers; morphology controlling; optical properties; band gap energy controlling

\section{Introduction}

Nanohybrid structures are very interesting materials and have attracted a considerable amount of attention from many researchers because of their remarkable physical and chemical properties that cannot be accomplished by the usual solid-state reactions [1-9]. This trend is very creative because the diverse properties of the different species can be collected in one material. The incorporation of two or more inorganic species, having one dimension or two dimensions in the nanoscale, is an efficient way to design hybrid material. The challenge is to produce a homogeneous and stable system of nanohybrids.

In order to minimize the degree of phase separation for the hybrid materials, layered double hydroxides can be useful in this trend because they have the ability to collect two or more inorganic metals in an order arrangement inside their layers with thicknesses of $0.48 \mathrm{~nm}$ [1-4]. In addition, organic or inorganic species can be intercalated inside their interlayered region through host-guest 
intercalation processes [5]. These intercalation processes occur through creating a positive charge on the nanolayers of layered double hydroxides (LDHs) because of the presence of divalent and trivalent metals together inside these nanolayers, which act as a host. Organic or inorganic anions intercalate to neutralize the positive charges of the nanolayers and act as guests. LDHs are defined by the general formula [M1- $\left.\mathrm{xM}^{*} \mathrm{x}(\mathrm{OH})_{2}\right]^{\mathrm{z}+}\left(\mathrm{A}^{\mathrm{n}-}\right)_{\mathrm{z} / \mathrm{n}} \cdot \mathrm{yH}_{2} \mathrm{O} . \mathrm{M}$ and $\mathrm{M}^{*}$ are divalent cations (e.g., $\mathrm{Zn}^{2+}, \mathrm{Fe}^{2+}$, $\mathrm{Mg}^{2+}, \mathrm{Ni}^{2+}, \mathrm{Cu}^{2+}$, or $\mathrm{Co}^{2+}$ ) and trivalent cations (e.g., $\mathrm{Cr}^{3+}, \mathrm{Al}^{3+}, \mathrm{Ga}^{3+}, \mathrm{In}^{3+}$, or $\mathrm{Fe}^{3+}$ ), respectively; $\mathrm{A}^{\mathrm{n}-}$ represents organic or inorganic anions [10-14]. Recently, a narrow number of monovalent and tetravalent cations such as lithium, titanium, tin, and zirconium was inserted in the host layers of LDH structures. However, there is no data available in the literature for silicon $\left(\mathrm{Si}^{4+}\right)$.

Cobalt and silicon are widely known to have major roles in coloring glasses [15], the photothermal conversion of solar energy [16], and in several technically orientated glass applications [17]. A combination of cobalt and silicon is employed in different applications [18-25] such as refractories materials, advanced ceramic industry, magnetic materials, ceramic pigment, electrical conductivity, batteries, catalysts, and gas sensors because of their remarkable magnetic, electrical, and optical properties in addition to their high oxidation activity and stabilization at high temperature.

In this trend, the photofunctional guest molecules can be assembled with the LDHs host layers containing photoactive metals to build a new type of host-guest nanohybrid materials with advanced photo-related performances such as a low band gap. Some positive effects can be obtained from the confinement of dual anions inside the nanolayered structures of multi-metal LDHs. The vibration and thermal motion of guests can be controlled in the confined interlayer space to improve the efficiency of the photoactive molecules and change their morphologies. In addition, the regular layers of multi-metal LDHs allow an ordered arrangement of different metals to minimize the degree of phase separation and obtain homogeneous nanohybrids.

In this study, our research focuses on a combination of cobalt and silicon through layered double hydroxides with different morphologies, although there is no data available for this material in the literature. In the same time, a dual anion intercalation process is used to control the morphology of LDHs. Nanofibers of Co-Si LDHs are prepared and characterized by different techniques. In addition, the crystalline structure and the morphology of $\mathrm{Co}-\mathrm{Si} \mathrm{LDHs}$ are developed by inserting other inorganic tetravalent metals such as titanium and zirconium. In addition, the optical properties of Co-Si LDHs are investigated and modified by combining with titanium and zirconium.

\section{Materials and Methods}

\subsection{Preparation of Nanostructures}

Urea hydrolysis is organized by controlling the temperature of its aqueous solution. The decomposition of urea occurs through two steps to produce cyanate or carbonate anions in addition to ammonium ion converting the medium of the solution from acidic to basic. By controlling the preparation conditions, $\mathrm{Co}-\mathrm{Si} \mathrm{LDH}$ was synthesized by precipitating cobalt and silicon during the production of cyanate anions from urea hydrolysis. A solution of cobalt nitrate $(0.03 \mathrm{~mol})$ was mixed with urea solution $(0.5 \mathrm{~mol})$ under vigorous stirring. Then, an aqueous solution of silicon chloride $(0.0096 \mathrm{~mol})$ was added to the mixture. The temperature of the reaction was adjusted at $80^{\circ} \mathrm{C}$. The reaction continued for $18 \mathrm{~h}$, noticing that urea was used as a $\mathrm{pH}$ controller and precipitant for the reaction. The silicon percentage was $24 \mathrm{~mole} \%$. By washing and filtration, the product was dehydrated under vacuum at room temperature. The sample was labeled here after as Co-Si LDHs.

To study the effect of zirconium on Co-Si LDHs, the above method was repeated by adding an aqueous solution of zirconyl chloride. The molar ratio of Si: $\mathrm{Zr}$ was 1:1. The temperature of the reaction was adjusted to $80^{\circ} \mathrm{C}$ for $18 \mathrm{~h}$. The percentage of both tetravalent metals was $24 \mathrm{~mole} \%$. In order to indicate the effect of titanium and zirconium, the same method was repeated through adding both titanium chloride and zirconyl chloride $(0.0096 \mathrm{~mol})$ to the urea solution. The molar ratio of Si:Zr:Ti was 1:1:1. The percentage of silicon, zirconium, and titanium was $24 \mathrm{~mole} \%$. 


\subsection{Physical Characterization}

Elemental analysis was achieved through an energy-dispersive X-ray spectrometer (EDX) with JEOL JED-2140, Japan. Powder X-ray diffraction (XRD) was performed on a Rigaku RINT 2200 (Japan) using CuK $\alpha$ (filtered) radiation $(\lambda=0.154 \mathrm{~nm})$ at $40 \mathrm{kV}$ and $20 \mathrm{~mA}$ between 1.8 and $50^{\circ}$. Scanning electron microscopy (SEM) was accomplished with a JEOL JSM-6330F, (15 kV/12 mA), Japan. Thermal analyses (Differential Thermal Analysis; DTA, Differential Thermal gravimetric; DTG, and Thermal gravimetric; TG) were carried out up to $800^{\circ} \mathrm{C}$ at a heating rate of $10^{\circ} \mathrm{C} / \mathrm{min}$ in a flow of gases using a Seiko SSC 5200 apparatus (Japan). Fourier Transform Infrared (FT-IR) spectroscopy was performed as $\mathrm{KBr}$ discs in the range of $425-4000 \mathrm{~cm}^{-1}$ by Horiba FT-720 (Japan).

The diffuse reflectance technique was used to measure the optical parameters of the nanomaterials by using a UV/VIS/NIR Shimadzu 3600 spectrophotometer (Shimadzu, Columbia, Maryland, United States). The spectrophotometer was equipped with an integrating sphere attachment (ISR-603) to measure solid materials, and the thickness of the sample was $3 \mathrm{~mm}$. Barium sulfate was used as the reflectance standard.

\section{Results}

\subsection{Scanning Electron Microscopy}

A scanning electron microscopy analysis of Co-Si LDHs was measured after coating with a platinum thin film to display clear images. Nanofibers and nanoneedles were observed for Co-Si LDHs, as shown in Figure 1. Figure 1b,d displayed individual fibers with diameters of $50 \mathrm{~nm}$. Meanwhile Figure $1 \mathrm{a}, \mathrm{c}$ revealed bundles of nanofibers. However, the morphology of the natural samples of layered double hydroxides, which consists of divalent and trivalent cations, is plate-like morphology [26,27]. It means that the presence of the tetravalent cations of silicon caused distortion or curvature for the nanolayers of $\mathrm{Co}-\mathrm{Si}$ LDHs. This distortion or curvature may be achieved through creating positive charges $(+2)$ by silicon and the insertion of dual anions for neutralizing these positive charges.

In case of the insertion of zirconium inside the Co-Si LDHs, SEM images showed plate-like morphology, which started to transform to fibrous morphology, as shown in Figure 2a. At the same time, other locations of the sample exhibited only fibrous morphology, as shown in Figure $2 \mathrm{~b}$. It is known that the crystals of hydrotalcite have a hexagonal plate-like morphology if carefully crystallized [26]. It means that the plate-like morphology of the LDHs, which was formed agreeing with the conventional LDHs, converted to nanofibers because of the presence of zirconium in the LDH structure. Energy dispersive X-ray spectrometer confirmed the presence of cobalt, zirconium, silicon, carbon, oxygen, and nitrogen on the structure of LDHs, as shown in Figure 2c.

The presence of carbon, oxygen, and nitrogen suggests that a dual anions intercalation process has occurred inside the interlayered region of the structures of the LDHs. It means that both silicon and zirconium may have a role in producing and trapping cyanate and nitrate anions inside their LDHs.

After the insertion of zirconium and titanium inside the structure of $\mathrm{Co}-\mathrm{Si} \mathrm{LDHs}$, plate-like morphology was observed with a thickness of $100 \mathrm{~nm}$ and dimensions a few micrometers in width, as seen in Figure 3. The individual plates of the LDHs have a hexagonal platy morphology, agreeing with hydrotalcite crystals. The different elements in these plates were identified through the energy dispersive X-ray spectrum, as shown in Figure 3c. The peaks of cobalt, silicon, zirconium, and titanium were observed on these plates, confirming the insertion of zirconium and titanium in the Co-Si LDHs. In addition, carbon, oxygen, and nitrogen were detected inside the structure of LDHs. 

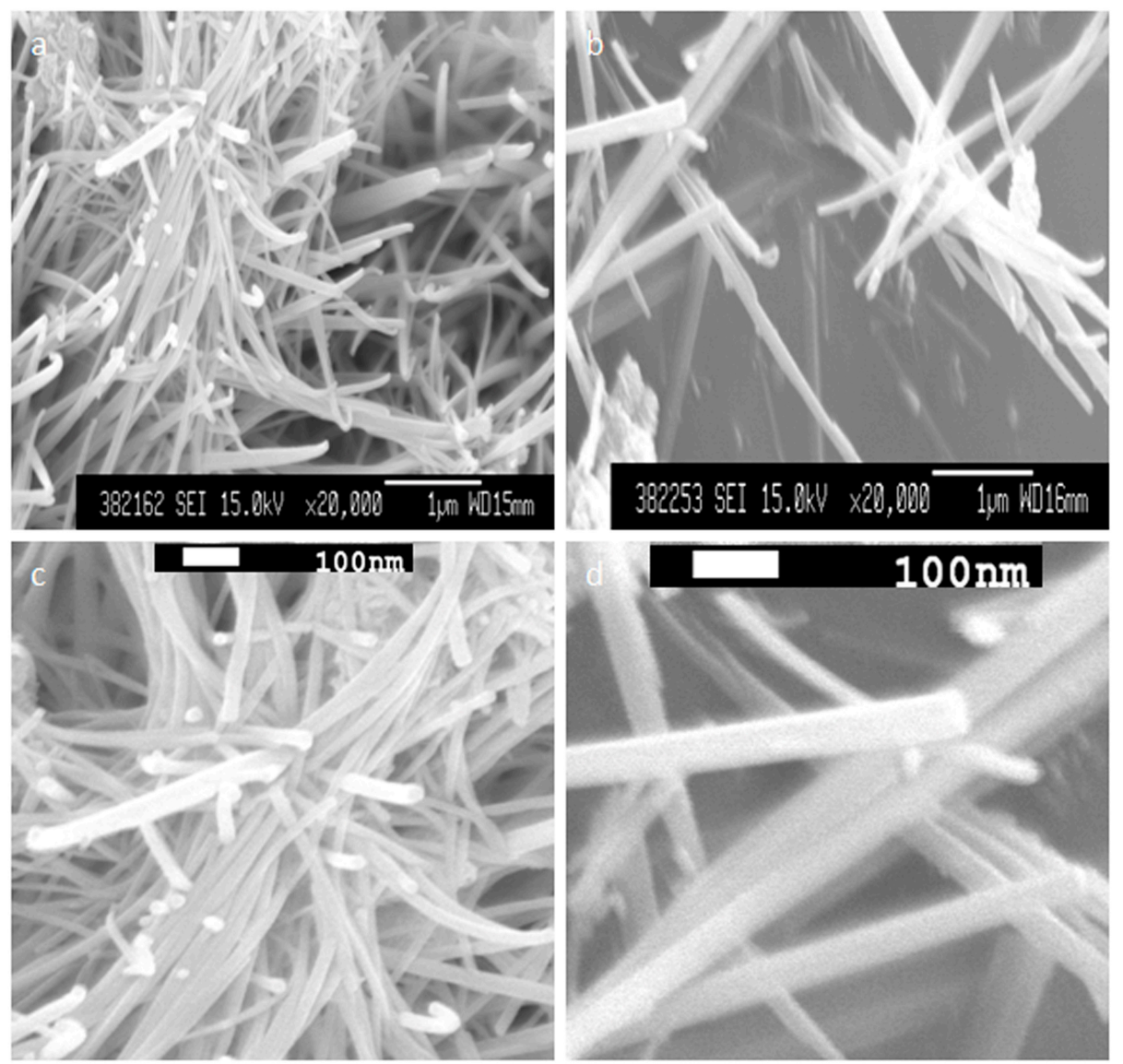

Figure 1. Scanning electron microscopy (SEM) images of Co-Si layered double hydroxides (LDHs). (a) Reaction time $16 \mathrm{~h},(\mathbf{b})$ reaction time $18 \mathrm{~h}$, (c) $16 \mathrm{~h}$ by magnification, (d) $18 \mathrm{~h}$ by magnification.
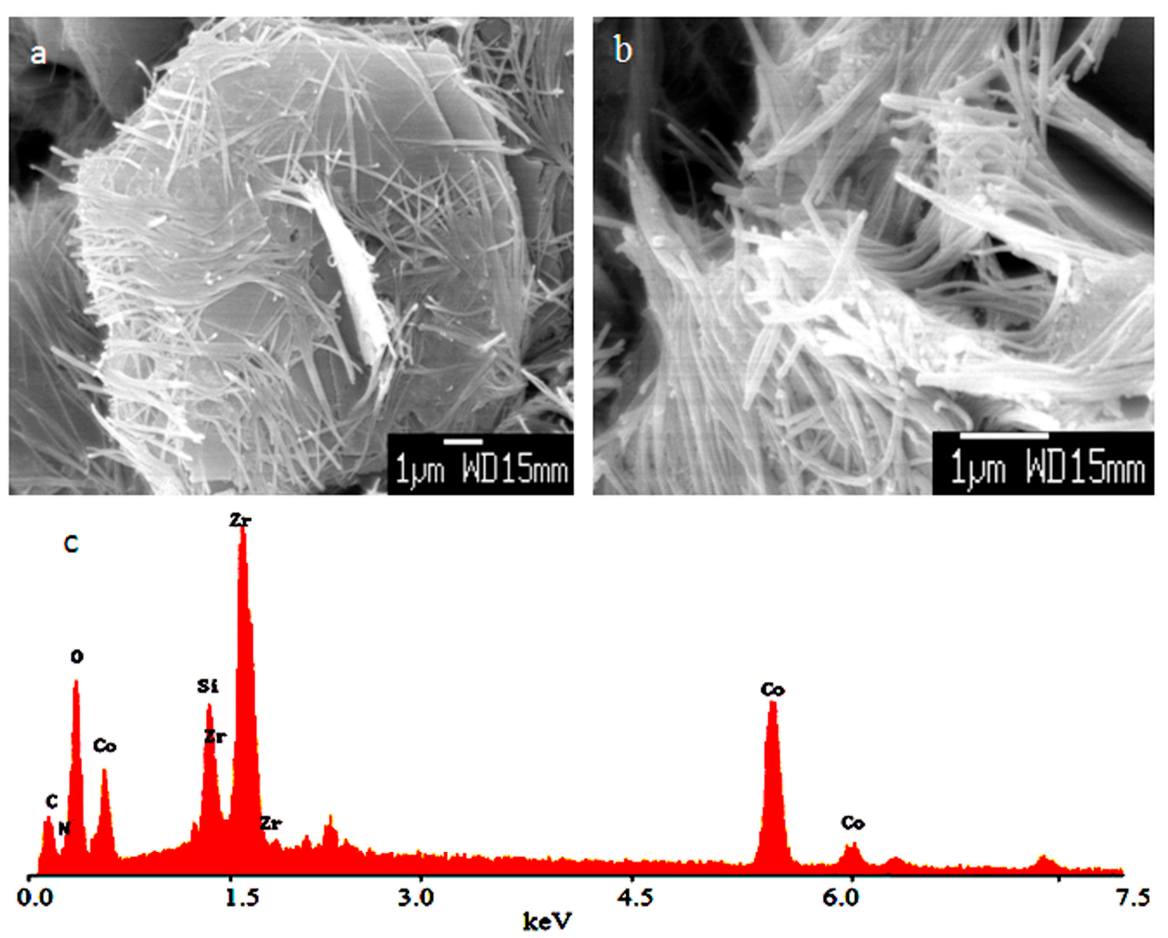

Figure 2. Co-Si LDHs after zirconium inclusion: (a) SEM image, (b) SEM image after magnification, (c) energy-dispersive X-ray spectrometer (EDX). 

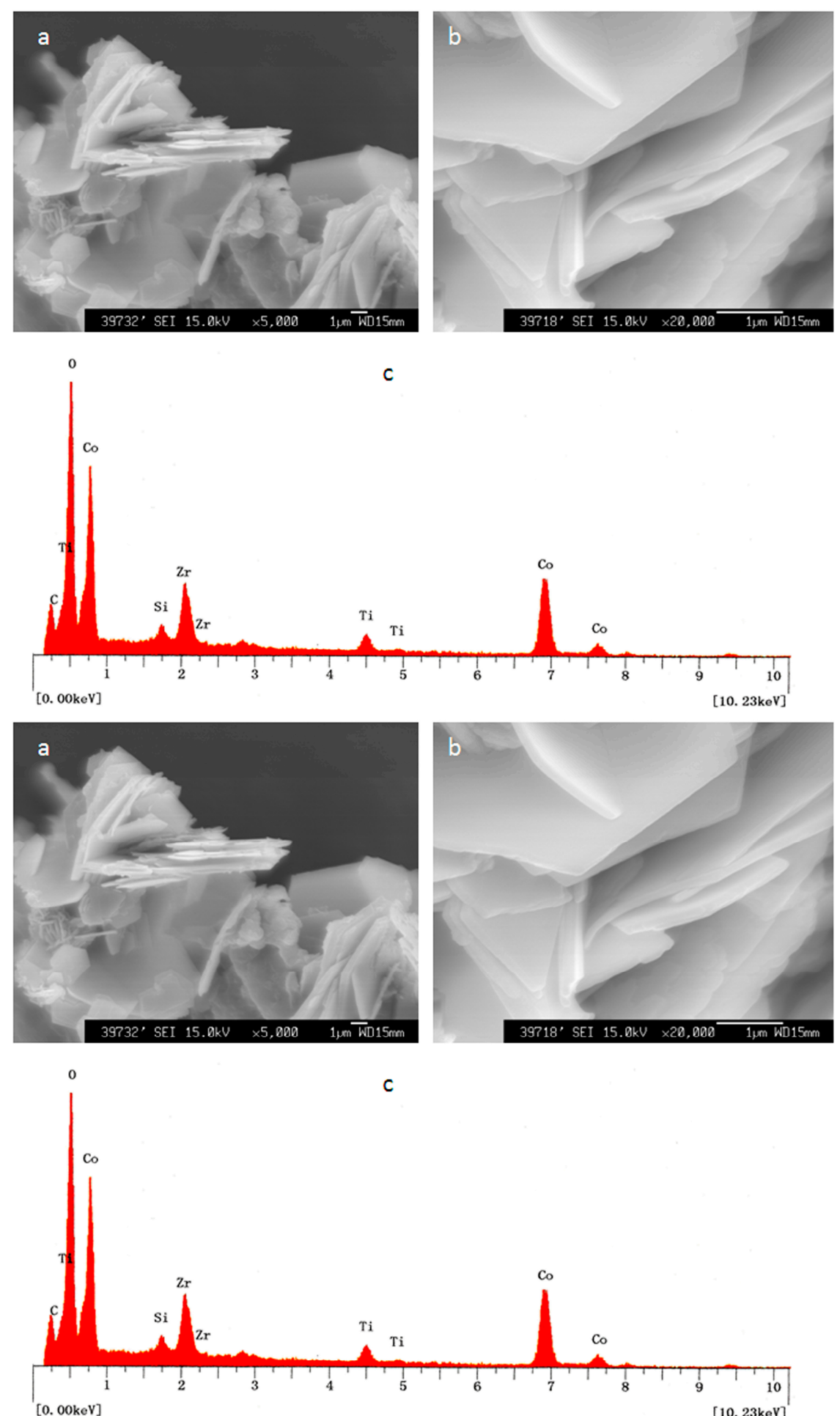

Figure 3. Co-Si LDHs after zirconium and titanium inclusion: (a) SEM image, (b) SEM image after magnification, (c) EDX.

\subsection{Powder X-Ray Diffraction}

Figure 4a displayed the X-ray diffraction pattern of Co-Si LDHs. It showed that Co-Si LDHs have a non-crystalline structure. After the insertion of zirconium cations, a clear nanolayered structure was observed, as shown in Figure $4 \mathrm{~b}$. The main peaks of brucite-like layers were observed, displaying the reflection of planes 003, 006, and 009. The c parameter, which was determined as three times the 
spacing for plane 003 (i.e., $3 \times 0.79=2.37 \mathrm{~nm}$ ), has a little shift from that previously published for synthetic and natural hydrotalcite, which was $2.31 \mathrm{~nm}$ [26].

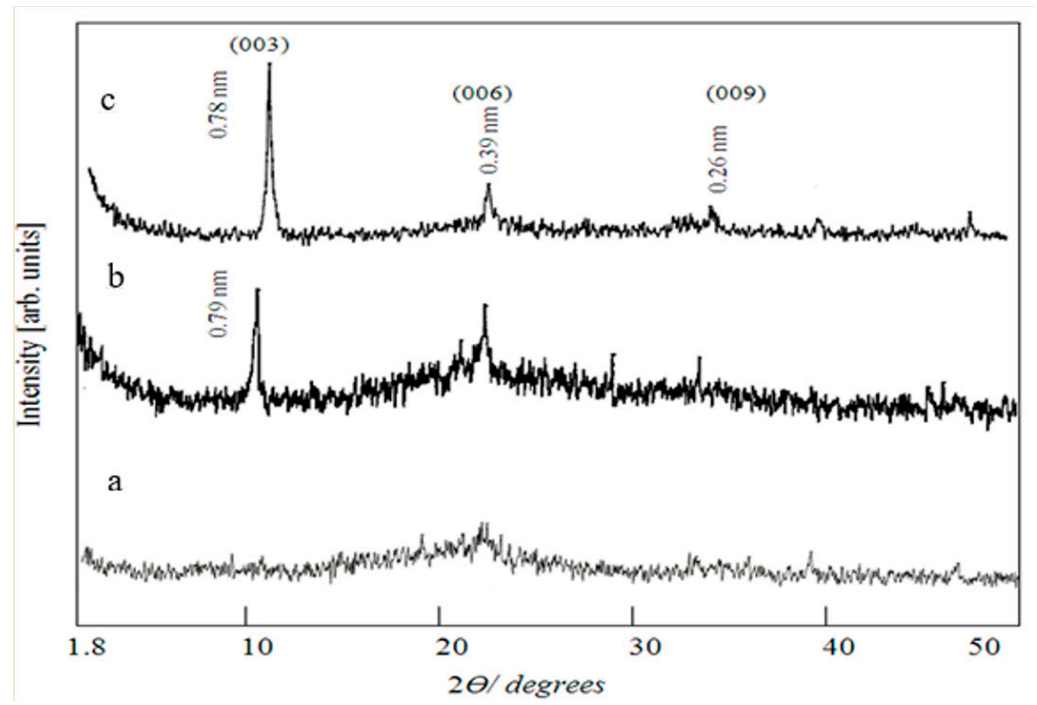

Figure 4. X-ray diffraction of Co-Si LDHs: (a) pure, (b) after zirconium inclusion, and (c) after zirconium and titanium inclusion.

By the insertion of titanium besides zirconium inside the nanolayers of Co-Si LDHs, the nanolayered structure was confirmed by a clear and sharp peak at $0.78 \mathrm{~nm}$, indicating the reflection of plane 003, which determines the interlayered spacing of LDHs. The other reflections of the planes 006 and 009 were also observed by the peaks at $0.39 \mathrm{~nm}$ and $0.26 \mathrm{~nm}$, respectively, as shown in Figure $4 \mathrm{c}$. These peaks have common features of layered materials such as strong peaks at low values of $2 \theta$ with symmetric and narrow shapes, while at high $2 \theta$ values, the peaks become weak and have less symmetric lines. These results indicated that the insertion of zirconium and titanium converted the amorphous structure of Co-Si LDHs to a crystalline structure.

\subsection{Thermal Analyses}

The thermal analyses (DTA, TG, and DTG) of the sample Co-Si LDHs are shown in Figure 5. The total weight loss of Co-Si LDHs was more than $26.8 \%$. The TG diagram illustrated that the removal of surface and intercalated water occurred through two stages. The surface water was $7.6 \mathrm{wt} \%$ and easily lost at $100{ }^{\circ} \mathrm{C}$, indicating an endothermic peak in the DTA curve and a clear peak in the DTG curve. Meanwhile, $3.3 \mathrm{wt} \%$ of the interlayered water was gradually lost up to $222{ }^{\circ} \mathrm{C}$, indicating that the water molecules strongly bonded with the interlayered anions. The decomposition of the interlayered anions happened through two stages, indicating dual interlayered anions. The first anion (8.7 $\mathrm{wt} \%)$ was sharply lost, exhibiting an endothermic peak in the DTA curve and a sharp peak in the DTG curve at $256{ }^{\circ} \mathrm{C}$. Meanwhile, the second anion was gradually lost with the dehydroxylation process of the nanolayers. This loss continued up to $800{ }^{\circ} \mathrm{C}$ and was more than $7.2 \mathrm{wt} \%$. These results concluded that the Co-Si LDHs have dual intercalated anions and a large amount of water inside the interlayered space. 


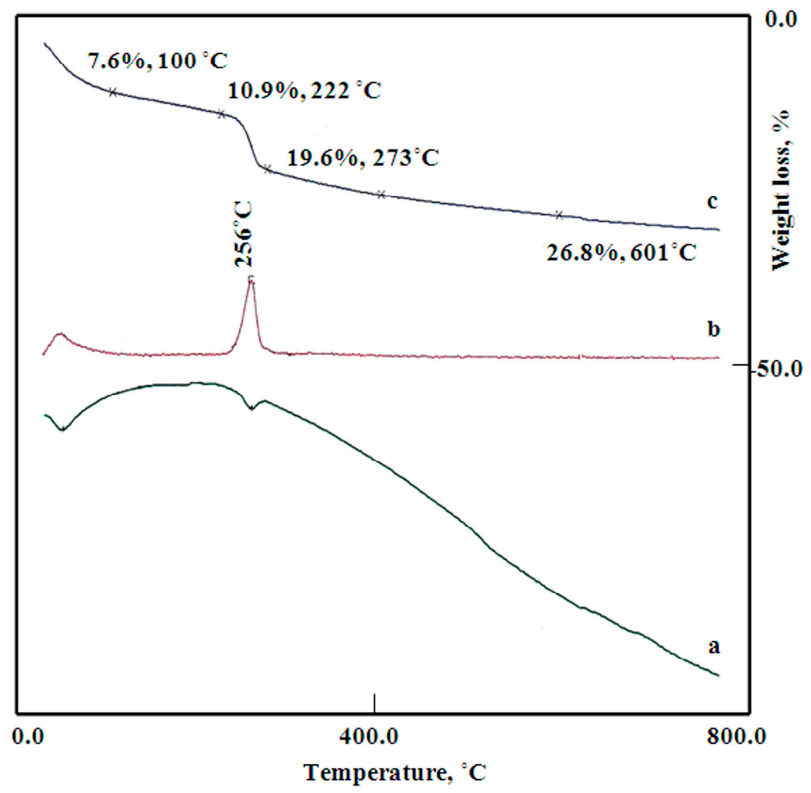

Figure 5. Thermal analyses of Co-Si LDHs (a) Differential Thermal Analysis; DTA, (b) Differential Thermal gravimetric; DTG, and (c) Thermal gravimetric; TG.

The thermal analyses (DTA, TG, and DTG) of Co-Si LDHs after the insertion of zirconium are shown in Figure 6. The TG diagram showed similar behavior for Co-Si LDHs before and after the inclusion of zirconium where the total weight loss occurred through four stages. The decomposition of the interlayered anions was observed as two weight losses in the TG diagram and two clear peaks in the DTG diagram. In addition, the DTA diagram showed two endothermic peaks at $250^{\circ} \mathrm{C}$ and $295^{\circ} \mathrm{C}$, agreeing with the decomposition of the interlayered anions. Two clear peaks mean that there are two different kinds of anions inside the LDH structure, confirming the dual anion intercalation process. These results indicated that there is similarity between the structures of $\mathrm{Co}-\mathrm{Si} \mathrm{LDH}$ before and after the insertion of zirconium.

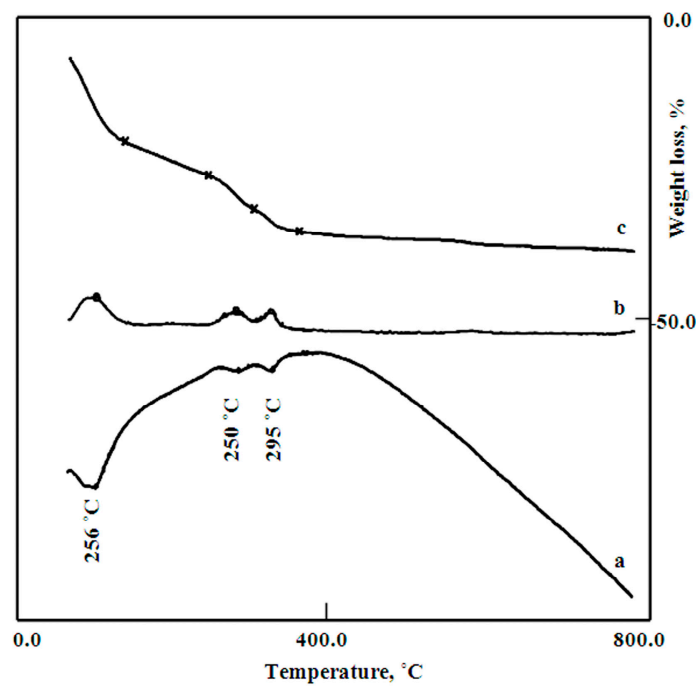

Figure 6. Thermal analyses of Co-Si LDHs after zirconium inclusion: (a) DTA, (b) DTG, and (c) TG.

The thermal analyses (DTG, DTA, and TG) of Co-Si LDHs after the insertion of zirconium and titanium were recorded as shown in Figure 7. The TG diagram showed only three weight losses. The first two weight losses belong to the adsorbed and the interlayered water, while the decomposition of the intercalated anions occurred through only one step, indicating that the LDH has one kind of the 
interlayered anions. The total weight loss is composed of $14.6 \%$ surface water, $3.4 \%$ interlayered water, and $12 \%$ interlayered anions. The DTG diagram showed only one peak at $258{ }^{\circ} \mathrm{C}$, confirming the presence of one kind of the interlayered anions. The DTA curve revealed one endothermic peak at $261{ }^{\circ} \mathrm{C}$ agreeing with the TG results. These results concluded that the insertion of titanium and zirconium inside the $\mathrm{Co}-\mathrm{Si} \mathrm{LDH}$ structure led to the intercalation of only one kind of anion inside its structure.

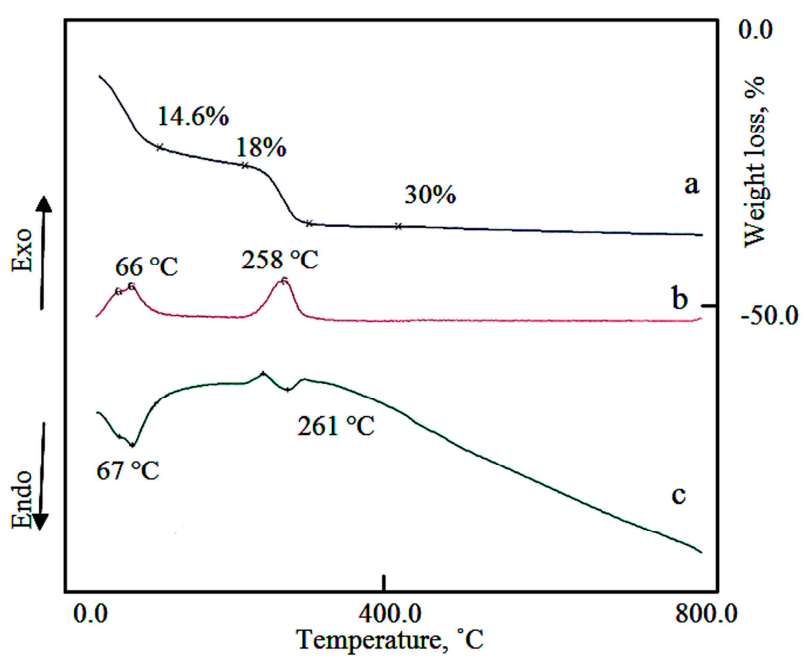

Figure 7. Thermal analyses of Co-Si LDHs after zirconium and titanium inclusion: (a) TG, (b) DTG, and (c) DTA.

\subsection{Infrared Spectra}

To identify the intercalated anions, an infrared spectrum of Co-Si LDHs after the insertion of zirconium is displayed in Figure 8a. Cyanate anions $\left(\mathrm{N} \equiv \mathrm{C}^{-} \mathrm{O}^{-}\right)$were observed by the appearance of a clear band at $2203 \mathrm{~cm}^{-1}$ corresponding to the vibrational mode of cyanate. The nitrate anions were also detected by observing two bands at $1384 \mathrm{~cm}^{-1}$ and $1495 \mathrm{~cm}^{-1}$ [28]. Strong and sharp bands were observed around $2856 \mathrm{~cm}^{-1}$. These bands are attributed to the stretching mode of $\mathrm{O}-\mathrm{H}$ belonging to the molecules of interlayered water that hydrogen-bonded to interlayered anions [28]. The sharpness of these bands suggests that there is a large number of water molecules hydrogen-bonded with the cyanate anions inside the interlayered space. This speculation was confirmed by the bending mode band of water molecules that was observed clearly close to $1637 \mathrm{~cm}^{-1}$ [29].

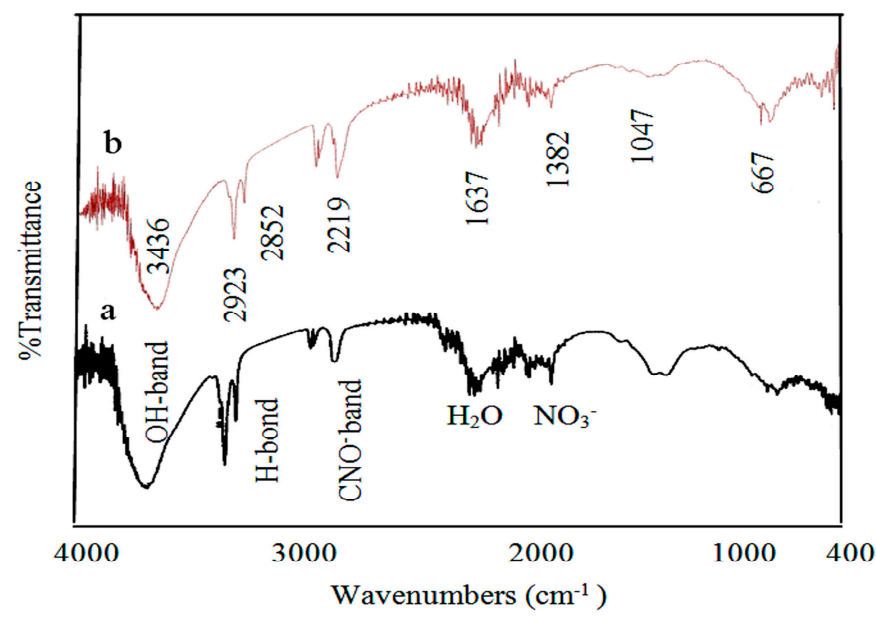

Figure 8. Infrared spectra of Co-Si LDHs: (a) after zirconium inclusion and (b) after zirconium and titanium inclusion. 
After inserting both zirconium and titanium into Co-Si LDHs, the absorption peak at $2204 \mathrm{~cm}^{-1}$ shifts to $2217 \mathrm{~cm}^{-1}$, indicating that the intercalated anions became isocyanate anions $\left({ }^{-} \mathrm{N}=\mathrm{C}=\mathrm{O}\right)$, as shown in Figure $8 \mathbf{b}[30]$. It means that cyanate anions transformed to isocyanate anions, according to the balance $\left(\mathrm{N} \equiv \mathrm{C}-\mathrm{O}^{-} \leftrightarrow{ }^{-} \mathrm{N}=\mathrm{C}=\mathrm{O}\right)$.

As can be noted in Figure 8b, traces of nitrate anions were also detected by a weak peak at $1382 \mathrm{~cm}^{-1}$ [28]. There is no peak shift for the vibrational mode of $\mathrm{NO}_{3}{ }^{-}$, suggesting that nitrate anions adopt a flat-lying configuration parallel to the hydroxide layer [31].

The effect of the presence of isocyanate and nitrate anions inside the interlayer space beside the hydroxide layers of the $\mathrm{LDH}$ structure showed a broad $\mathrm{OH}$ vibration band around $3500 \mathrm{~cm}^{-1}$ [28-31]. This effect was extending by increasing the hydrogen bonds between the water molecules and the interlayered anions producing clear peaks around $2923 \mathrm{~cm}^{-1}$ [32]. The presence of water molecules was confirmed by observing a clear band at $1637 \mathrm{~cm}^{-1}$ corresponding to its bending mode [28].

\subsection{Conversion Mechansim of Nanolayers to Nanofibers by Dual Anions Intercalation}

It is known that the most familiar morphology of LDHs is plate-like morphology. The experimental results demonstrated that there is a relation between the morphology of LDH and the insertion of silicon, zirconium, and titanium inside the nanolayers of LDH. When silicon was inserted in the sheets of the LDHs, the conventional morphology of the LDHs transformed from plates to nanofibers. In the same trend, the insertion of zirconium beside silicon converted the plate-like morphology of LDHs to nanofibers and nanoneedles. However, the insertion of titanium beside both silicon and zirconium prevented this transformation from plates to nanofibers and showed plate-like morphology. According to the thermal analyses, this relation appears between the decomposition rate of the interlayered anions of each LDH and its morphology.

In the case of $\mathrm{Co}-\mathrm{Si} \mathrm{LDHs}$ before and after the insertion of zirconium, the decomposition of the interlayered anions happened through two stages. It means that their nanolayered structures have formed through a dual anions intercalation process. This finding was confirmed by infrared results where these results showed clear bands for nitrate and cyanate anions in the structure of Co-Si LDHs after the insertion of zirconium.

The cyanate anions were formed during the urea hydrolysis, as shown in the following Equation (1):

$$
\left(\mathrm{NH}_{2}\right)_{2} \mathrm{CO}+\mathrm{H}_{2} \mathrm{O} \rightarrow \mathrm{NH}_{4}^{+}+\mathrm{CNO}^{-}+\mathrm{H}^{+}+\mathrm{OH}^{-}
$$

Many researchers [33] reported that ammonia and cyanate anions were produced from urea hydrolysis. In addition to cyanate anions, the nitrate anions are accompanied with the beginning salts.

According to the dual anions intercalation process, the nanofibers and nanoneedles morphologies of $\mathrm{Co}-\mathrm{Si} \mathrm{LDHs}$ could be explained. The intercalated cyanate anions $(-1)$ have two routes or directions to neutralize the positive charges $(+2)$ of the nanolayers of the LDHs. The first route is attacking the positive charge by two anions of cyanate from only one side of the nanolayer. The second route is attacking the positive charge by one anion of cyanate to each side of the nanolayers. If the intercalated cyanate anions followed the first route, the cyanate anions would have strong repulsion, and the steric hindrance among their cyanide groups would lead to curling for the nanolayers of LDHs. This curling converted the shape of plates to nanofibers or nanoneedles. In the presence of nitrate as secondary anions in the LDH structure, the intercalated cyanate anions follow the first route, avoiding the repulsion with nitrate anions to build nanofibers or nanoneedles. By this explanation, we can suggest a model for the nanofibers and nanoneedles of $\mathrm{Co}-\mathrm{Si} \mathrm{LDHs}$, as shown in Figure 9. 


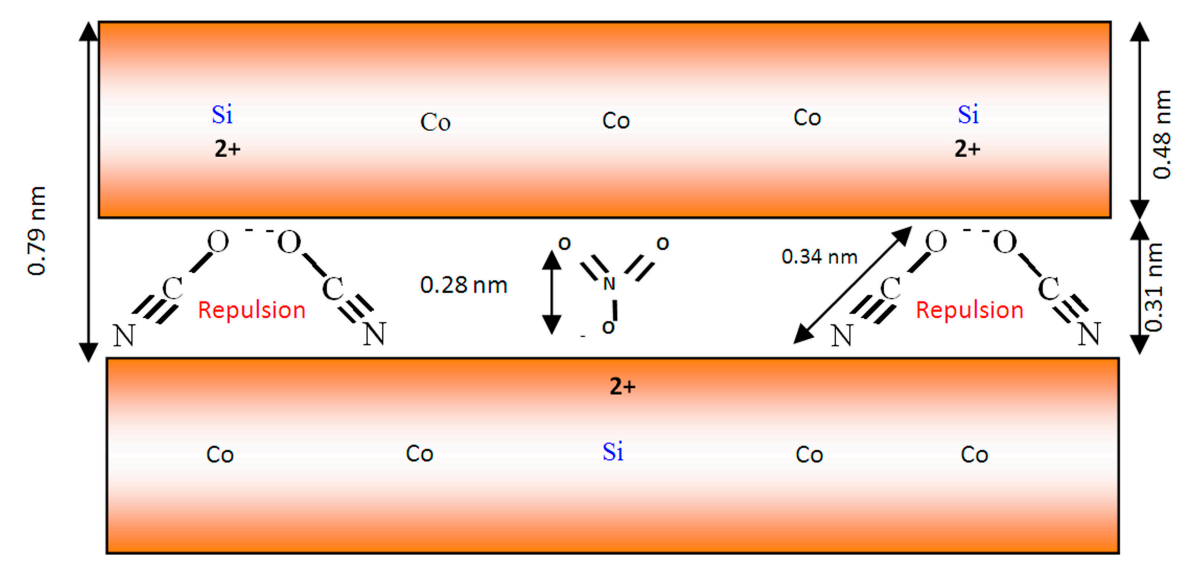

Figure 9. Schematic representation for the nanofibers and nanoneedles of Co-Si LDHs.

By using both the XRD results and the known thickness of the brucite-like layer, $0.48 \mathrm{~nm}$, the interlayer spacing available for the anion was calculated as $0.31 \mathrm{~nm}$. The size of the $\mathrm{NCO}^{-}$anion is $0.34 \mathrm{~nm}$, and the thickness of a flat-lying $\mathrm{NO}_{3}{ }^{-}$is $0.28 \mathrm{~nm}$. Therefore, it was considered that cyanate anions connect with the positive charge of the layers through one side in order to neutralize the positive charge of tetravalent cation and build the nanofibers' morphology, as shown in Figure 9. The presence of nitrate anions among the layers may direct the cyanate anions to attack the positive charge from only one side to build nanofibers.

In the case of $\mathrm{Co}-\mathrm{Si} \mathrm{LDH}$, after inserting both zirconium and titanium, the main interlayered anions are made out of isocyanate, in addition to traces of nitrate. Therefore, the intercalation of cyanate anions followed the second route, forming plate-like morphology, as shown in Figure 10.

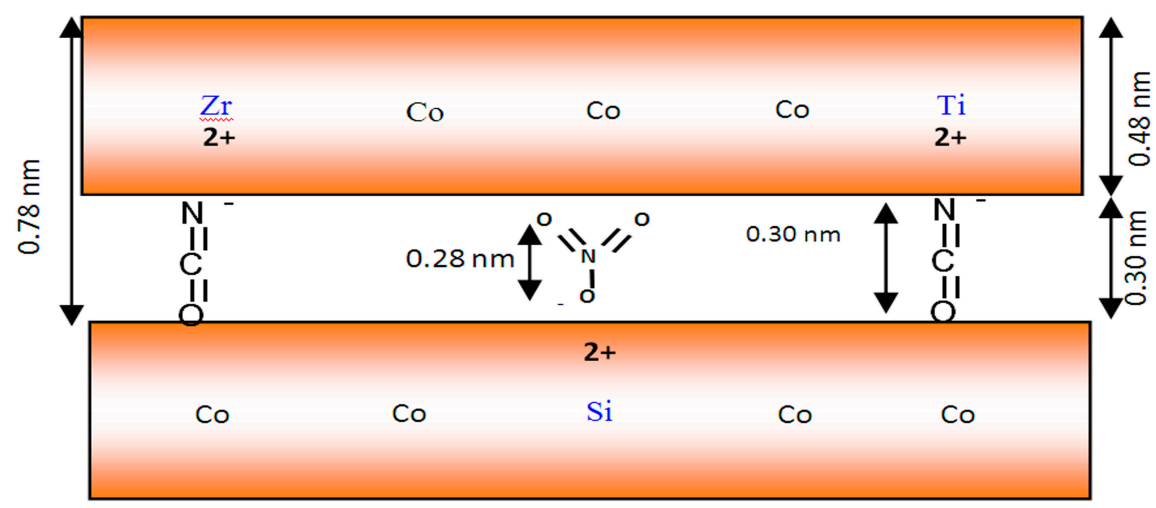

Figure 10. Schematic representation for the plates of Co-Si LDHs after zirconium and titanium inclusion.

\subsection{Optical Properties}

The optical properties of Co-Si LDHs before and after the inclusion of zirconium and titanium were investigated by diffuse reflectance spectroscopy in the range of $200-700 \mathrm{~nm}$. In case of Co-Si LDHs, it is clear that the spectrum is dominated by absorption in the UV region with its maximum at $230 \mathrm{~nm}$, as shown in Figure 11. With the inclusion of zirconium in Co-Si LDHs, there is a shift of absorption toward the visible region. It showed a triplet of bands at $250 \mathrm{~nm}, 350 \mathrm{~nm}$, and $550 \mathrm{~nm}$. In the same trend, the insertion of titanium and zirconium in the Co-Si LDH structures caused a little shift of the maximum bands from $250 \mathrm{~nm}$ and $350 \mathrm{~nm}$ to $275 \mathrm{~nm}$ and $375 \mathrm{~nm}$, respectively. 


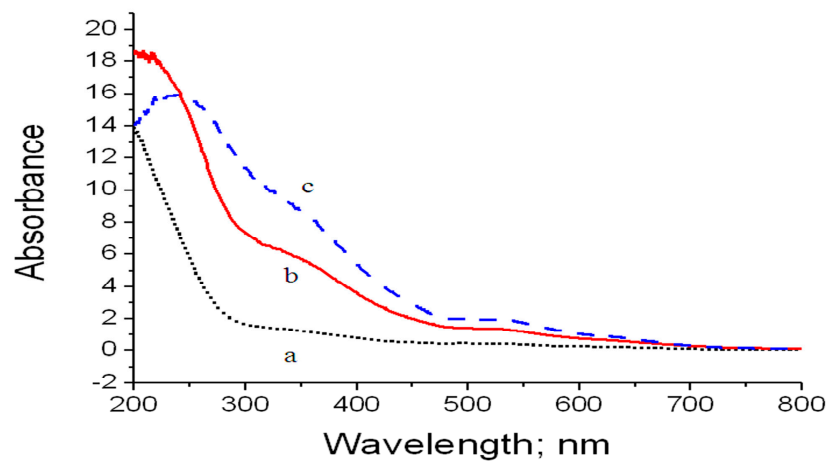

Figure 11. Absorbance of Co-Si LDHs: (a) pure, (b) after zirconium inclusion, and (c) after zirconium and titanium inclusion.

The process of light reflectance by the prepared materials is related to their electronic structures. Therefore, the diffuse reflectance results have been used for calculating the band gap energy. The optical band gap energy was determined by a Tauc equation [34]. The Kubelka-Munk relation is used to convert the diffuse reflectance into an absorption coefficient [35]. The absorption coefficient $(A b s)=(1-R)^{2} / 2 R$, where $\mathrm{R}$ is the reflectance. Accordingly, the Tauc relation becomes $(\mathrm{Abs} . \mathrm{E})=\mathrm{A}\left(\mathrm{E}-\mathrm{Eg}_{\mathrm{g}}\right)^{1 / 2}$. It expresses the direct transition, thus showing direct band gap energy $\left(E_{g}\right)$. The relation of both $(A b s . E)^{2}$ and $(E)$ for the prepared materials is displayed in Figure 12. The direct band gap values were determined by extrapolating the linear regions of these plots to $(\mathrm{Abs} . \mathrm{E})^{2}=0$. The band gap energy of Co-Si LDHs was $4.4 \mathrm{eV}$. A sharp reduction of the band gap was observed with the inclusion of zirconium, where the band gap of Co-Si LDHs became $2.95 \mathrm{eV}$. The reduction of the band gap continued with the insertion of titanium in the LDH structure giving $2.8 \mathrm{eV}$.

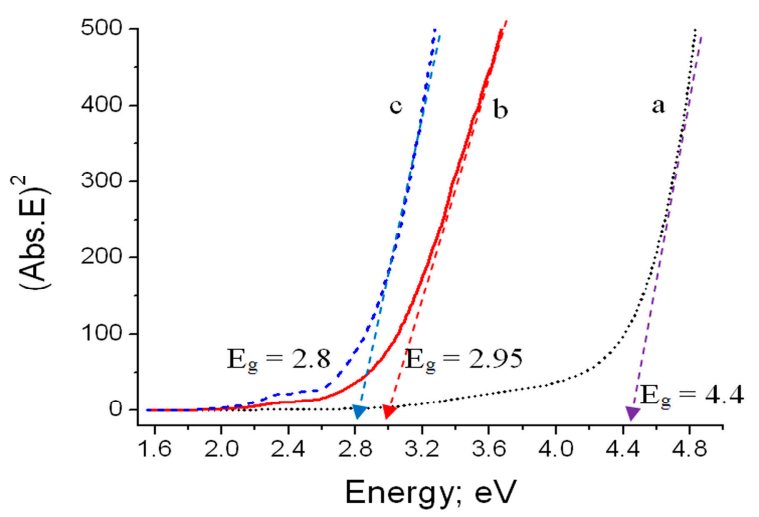

Figure 12. Band gap energy of Co-Si LDHs: (a) pure, (b) after zirconium inclusion, and (c) after zirconium and titanium inclusion.

It is clear that the optical properties of Co-Si LDHs were improved by introducing zirconium and titanium into its nanolayers. This improvement was observed as a significant red shift in the absorption edge of $\mathrm{Co}-\mathrm{Si}$ LDHs toward the visible light region. This shift was confirmed by a reduction in the band gap energy of Co-Si LDHs. This behavior could be explained by inducing a new energy level into the main band gap because of the new bands of $\mathrm{Co}(\mathrm{II})-\mathrm{O}-\mathrm{Zr}(\mathrm{IV})$ and $\mathrm{Co}(\mathrm{II})-\mathrm{O}-\mathrm{Ti}(\mathrm{IV})$ that were introduced in the LDHs structure. These new bands could change the band gap energy and improve the visible light absorption properties of the LDHs [36]. These results indicate the effective electronic coupling between $\mathrm{Co}(\mathrm{II})-\mathrm{O}-\mathrm{Si}(\mathrm{IV})$ and $\mathrm{Co}(\mathrm{II})-\mathrm{O}-\mathrm{Zr}(\mathrm{IV})$ in addition to $\mathrm{Co}(\mathrm{II})-\mathrm{O}-\mathrm{Si}(\mathrm{IV})$ and $\mathrm{Co}(\mathrm{II})-\mathrm{O}-\mathrm{Ti}(\mathrm{IV})$ in the $\mathrm{LDH}$ structures. 


\section{Discussion}

The present research has a dual aim of synthesizing nanofibers of Co-Si LDHs for the first time and developing their optical properties to be suitable for designing optical nanodevices. In this trend, nanofibers and nanoneedles of $\mathrm{Co}-\mathrm{Si} \mathrm{LDH}$ were prepared and modified by the inclusion of zirconium and titanium inside the nanolayers of the LDH structure. SEM images showed individual nanofibers of $\mathrm{Co}-\mathrm{Si} \mathrm{LDHs}$. In case of the inclusion of zirconium inside the nanolayers of Co-Si LDHs, the nanolayered structure was confirmed by $\mathrm{X}$-ray diffraction, and the nanofibers morphology became clearer. In addition, the band gap energy of $\mathrm{Co}-\mathrm{Si}$ LDHs shifted to be $2.95 \mathrm{eV}$ after inserting zirconium, and became more effective in the visible light region. Through titanium inclusion beside zirconium inside Co-Si LDHs, the nanofiber morphology converted to become plate-like morphology, and the band gap energy decreased to a lower value to become $2.8 \mathrm{eV}$.

These effective changes of $\mathrm{Co}-\mathrm{Si} \mathrm{LDHs}$ could be explained by inducing new energy levels into the main band gap because of the new bands of $\mathrm{Co}(\mathrm{II})-\mathrm{O}-\mathrm{Zr}(\mathrm{IV})$ and $\mathrm{Co}(\mathrm{II})-\mathrm{O}-\mathrm{Ti}(\mathrm{IV})$ that were introduced into the LDH structure. Meanwhile, the formation mechanism of the nanofibers could be clarified through a dual anions intercalation process. By intercalating cyanate and nitrate anions in the same interlayered region of the $\mathrm{Co}-\mathrm{Si} \mathrm{LDH}$ structure, strong repulsion and steric hindrance occurred among their cyanide groups, leading to curling for the nanolayers of LDH. This curling converted the shape of plates to nanofibers or nanoneedles.

It has been known that the performance of optical materials is controlled by main two factors. The first factor is the band gap energy of the material. The second factor depends on the electron-hole recombination process [37]. To maximize these two factors, the separation of the photogenerated electron-hole pairs should be enhanced, and the light absorption must shift toward the visible light region.

Comparing with the most familiar optical materials, $\mathrm{TiO}_{2}$ and $\mathrm{ZnO}$, the band gap energies of $\mathrm{Co}-\mathrm{Si} \mathrm{LDHs}$ after inserting zirconium and titanium are lower than those of $\mathrm{TiO}_{2}$ and $\mathrm{ZnO}$. In addition, the nanofibers' morphology decreases the rate of electron-hole recombination by the mobility of electrons through the nanofibers.

Finally, based on the above considerations, we can conclude that Co-Si LDHs after inserting zirconium and titanium are considered as promising candidates for optical applications such as photocatalysis. In addition, the nanofibers and nanoneedles are suitable components for designing optical nanodevices.

Author Contributions: Conceptualization, O.S. and A.A.; methodology, O.S.; software, O.S.; validation, O.S., N.S. and A.O.; formal analysis, A.A.; investigation, N.S.; resources, A.O.; data curation, N.S.; writing-original draft preparation, A.A.; writing-review and editing, O.S.; visualization, O.S.; supervision, O.S.; project administration, O.S.; funding acquisition, O.S.

Funding: This research was funded by the Deanship of Scientific Research in King Faisal University (Saudi Arabia), grant number 186289, and the APC was funded by the same grant number, 186289.

Acknowledgments: The authors acknowledge the Deanship of Scientific Research at King Faisal University (Saudi Arabia) for the financial support under Nasher Track (Grant No. 186289).

Conflicts of Interest: The authors declare no conflict of interest.

\section{References}

1. Wu, X.; Li, B.; Wen, X. Synthesis and adsorption properties of hierarchical Fe3O4@MgAl-LDH magnetic microspheres. J. Nanopart. Res. 2017, 19, 131-141. [CrossRef]

2. Al-Hossainy, A.F.; Ibrahim, A.; Zoromba, M. Synthesis and characterization of mixed metal oxide nanoparticles derived from Co-Cr layered double hydroxides and their thin films. J. Mater. Sci. Mater. Electron. 2019, 30, 11627-11642. [CrossRef]

3. Li, Z.; Zhang, Q.; Liu, X.; Wu, L.; Hu, H.; Zhao, Y. One-step mechanochemical synthesis of plasmonic Ag/Zn-Al LDH with excellent photocatalytic activity. J. Mater. Sci. 2018, 53, 12795-12806. [CrossRef] 
4. Li, Y.; Shan, L.; Sui, Y.; Qi, J.; Wei, F.; He, Y.; Meng, Q.; Ren, Y.; Liu, J. Ultrathin Ni-Co LDH nanosheets grown on carbon fiber cloth via electrodeposition for high-performance supercapacitors. J. Mater. Sci. Mater. Electron. 2019, 30, 13360-13371. [CrossRef]

5. Zhu, H.; Huang, X.; Wang, Z.; Kong, L.; Chen, M.; Wang, F. The remarkably improved filler dispersion and performance of SSBR/BR by core-shell structure SiO2@ LDH nanocomposites. SN Appl. Sci. 2019, 1, 345-354. [CrossRef]

6. Tadiello, L.; D’Arienzo, M.; Di Credico, B.; Scotti, R.; Hanel, T.; Matějka, L.; Mauri, M.; Morazzoni, F.; Simonutti, R.; Špírková, M. The filler-rubber interface in styrene butadiene nanocomposites with anisotropic silica particles: Morphology and dynamic properties. Soft Matter 2015, 11, 4022-4033. [CrossRef]

7. Tang, Z.H.; Zhang, L.Q.; Feng, W.J.; Guo, B.C.; Liu, F.; Jia, D.M. Rational design of graphene surface chemistry for high-performance rubber/ graphene composites. Macromolecules 2014, 47, 8663-8673. [CrossRef]

8. Araby, S.; Meng, Q.S.; Zhang, L.Q.; Zaman, I.; Majewski, P.; Ma, J. Elastomeric composites based on carbon nanomaterials. Nanotechnology 2015, 26. [CrossRef]

9. Tang, Z.H.; Zhang, C.F.; Wei, Q.Y.; Weng, P.J.; Guo, B.C. Remarkably improving performance of carbon black-filled rubber composites by incorporating MoS2 nanoplatelets. Compos. Sci. Technol. 2016, 132, 93-100. [CrossRef]

10. Li, C.; Dou, Y.; Liu, J.; Chen, Y.; He, S.; Wei, M.; Evans, D.G.; Duan, X. Synthesis of supported Ni@(RhNi-alloy) nanocomposites as an efficient catalyst towards hydrogen generation from N2H4BH3. Chem. Commun. 2013, 49, 9992-9994. [CrossRef]

11. Shao, M.; Ning, F.; Zhao, J.; Wei, M.; Evans, D.G.; Duan, X. Preparation of Fe3O4@SiO2@layered double hydroxide core-shell microspheres for magnetic separation of proteins. J. Am. Chem. Soc. 2012, 134, 1071-1077. [CrossRef] [PubMed]

12. Vialat, P.; Leroux, F.; Taviot-Gueho, C.; Villemure, G.; Mousty, C. Insights into the electrochemistry of (CoxNi(1-x))2Al-NO3 Layered Double Hydroxides. Electrochim. Acta 2013, 107, 599-610. [CrossRef]

13. Choi, S.J.; Choy, J.H. Layered double hydroxide nanoparticles as target-specific delivery carriers: Uptake mechanism and toxicity. Nanomedicine 2011, 6, 803-814. [CrossRef] [PubMed]

14. Yan, D.; Lu, J.; Wei, M.; Evans, D.G.; Duan, X. Recent advances in photofunctional guest/layered double hydroxide host composite systems and their applications: Experimental and theoretical perspectives. J. Mater. Chem. 2011, 21, 13128-13139. [CrossRef]

15. Durana, A.; Fernandez Navarroa, J.M.; Casariegob, P.; Joglarb, A. Optical properties of glass coatings containing Fe and Co. J. Non-Cryst. Solids 1986, 82, 391-399. [CrossRef]

16. Niklasson, G.A.; Granqvist, C.G. Optical properties and solar selectivity of coevaporated Co-Al2O3 composite films. J. Appl. Phys. 1984, 55, 3382-3410. [CrossRef]

17. Sambasiva Rao, M.V.; Rajyasree, C.; Narendrudu, T.; Suresh, S.; Suneel Kumar, A.; Veeraiah, N.; Krishna Rao, D. Physical and spectroscopic properties of multi- componemt $\mathrm{Na} 2 \mathrm{O}-\mathrm{PbO}-\mathrm{Bi} 2 \mathrm{O} 3-\mathrm{SiO} 2$ glass ceramics with Cr2O3 as nucleating agent. Opt. Mater. 2015, 47, 315-322. [CrossRef]

18. Ali, A.A.; Ahmed, I.S. Sol-gel auto-combustion fabrication and optical properties of cobalt orthosilicate: Utilization as coloring agent in polymer and ceramic. Mater. Chem. Phys. 2019, 238. [CrossRef]

19. El Hadri, M.; Ahamdane, H.; Raghni, M.E.I. Effect of sol-gel method on color properties of the classical cobalt olivine (Co2 SiO4) ceramic pigment. Bull. Mater. Sci. 2017, 40, 375-382. [CrossRef]

20. Lottermoser, W.; Fuess, H. Magnetic structure of the orthosilicates Mn2SiO4 and Co2SiO4. Phys. Status Solidi (A) 1988, 109, 589-595. [CrossRef]

21. Mueller, F.; Bresser, D.; Minderjahn, N.; Kalhoff, J.; Menne, S.; Krueger, S.; Winter, M.; Passerini, S. Cobalt orthosilicate as a new electrode material for secondary lithium ion batteries. Dalton Trans. 2014, 43, 15013-15021. [CrossRef] [PubMed]

22. Hirsch, L.M. Electrical conduction of Co2SiO4. Phys. Chem. Miner. 1990, 17, 187-190. [CrossRef]

23. Cantalini, C.; Post, M.; Buso, D.; Guglielmi, M.; Martucci, A. Gas sensing properties of nanocrystalline $\mathrm{NiO}$ and Co3O4 in porous silica sol-gel films. Sens. Actuators B Chem. 2005, 108, 184-192. [CrossRef]

24. Bayat, S.; Sobhani, A.; Salavati-Niasari, M. Co2SiO4 nanostructures/nanocomposites: Synthesis and investigations of optical, magnetic, photocatalytic, thermal stability and flame retardant properties. J. Mater. Sci. Mater. Electron. 2018, 29, 7077-7089. [CrossRef]

25. Kantam, M.L.; Rao, B.P.C.; Reddy, R.S.; Sekhar, N.; Sreedhar, B.; Choudary, B. Aerobic epoxidation of olefins catalyzed by Co-SiO2 nanocomposites. J. Mol. Catal. A Chem. 2007, 272, 1-5. [CrossRef] 
26. Saber, O. Improvement of optical properties and thermal stability of poly vinyl alcohol using salicylic acid confined in nanohybrid material. Polym. Bull. 2012, 68, 209-222. [CrossRef]

27. Hansen, H.; Koch, C. Synthesis and characterization of pyroaurite. Appl. Clay Sci. 1995, 10, 5-19. [CrossRef]

28. Bao, W.; Tian, H.; Jiang, Y.; Zhu, K.; Zhang, R.; Tan, Y.; Li, W.; Yu, Z.; Wang, L. Controlled preparation of Ni-Al $\mathrm{LDH}-\mathrm{NO} 3$ by a dual-anion intercalating process for supercapacitors. Ionics 2019, 25, 3859-3866. [CrossRef]

29. Saber, O.; Gobara, H.M.; Al Jaafari, A.A. Catalytic activity and surface characteristics of layered $\mathrm{Zn}-\mathrm{Al}-\mathrm{Si}$ materials supported platinum. Appl. Clay Sci. 2011, 53, 317-325. [CrossRef]

30. Faramawy, S.; Zaki, T.; Sakr, A.A.E.; Saber, O.; Aboul-Gheit, A.K.; Hassan, S.A. The activity of Mg-Al layered double hydroxides intercalated with nitrogen containing anions towards the removal of carbon dioxide from natural gas. J. Nat. Gas Sci. Eng. 2018, 54, 72-82. [CrossRef]

31. Witzke, T.; Torres-Dorante, L.; Bullerjahn, F.; Pollmann, H. Minerals as Advanced Materials II; Krivovichev, S.V., Ed.; Springer: Berlin, Germany, 2012.

32. Kleemann, M.; Elsener, M.; Koebel, M.; Wokaun, A. Hydrolysis of isocyanic acid on SCR catalysts. Ind. Eng. Chem. Res. 2000, 39, 4120-4126. [CrossRef]

33. Wang, S.F.; Gu, F.; Lu, M.K.; Cheng, X.F.; Zou, W.G.; Zhou, G.J.; Wang, S.M.; Zhou, Y.Y. Synthesis and photoluminescence characteristics of Dy3+-doped $\mathrm{ZnAl} 2 \mathrm{O} 4$ nanocrystals via a combustion process. J. Alloy. Compd. 2005, 394, 255-258. [CrossRef]

34. Bai, H.; Liu, Z.; Sun, D.D. The design of a hierarchical photocatalyst inspired by natural forest and its usage on hydrogen generation. Int. Hydrogen Energy 2012, 37, 13998-14008. [CrossRef]

35. Kim, S.J.; Lee, Y.; Lee, D.K.; Lee, J.W.; Kang, J.K. Efficient Co-Fe layered double hydroxide photocatalysts for water oxidation under visible light. J. Mater. Chem. A 2014, 2, 4136-4139. [CrossRef]

36. Anand, G.T.; Kennedy, L.J.; Vihaya, J.J. Microwave combustion synthesis, structural, optical and magnetic properties of ZnCoAl2O4 spinal nanostructures. J. Alloy. Compd. 2013, 581, 558-566. [CrossRef]

37. Seyed Dorraji, M.S.; Rasoulifard, M.H.; Daneshvar, H.; Vafa, A.; Amani-Ghadim, A.R. ZnS/ZnNiAl-LDH/GO nanocomposite as a visible-light photocatalyst: Preparation, characterization and modeling. J. Mater. Sci. Mater. Electron. 2019, 30, 12152-12162. [CrossRef] 